Vittalle - Revista de Ciências da Saúde v. 31, n. 1 (2019) 15-26

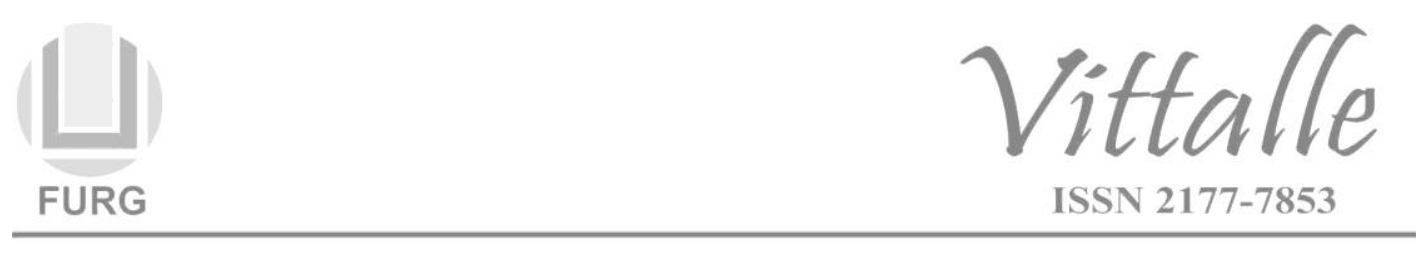

\title{
O ensino de ciências e os laboratórios escolares no Ensino Fundamental
}

\author{
Salete de Lourdes Cardoso Santana ${ }^{*}$, Edward Frederico Castro Pessano, Dandara Fidelis \\ Escoto, Geovana da Cruz Pereira, Cláudia Alves Ortiz Gularte, Vanderlei Folmer
}

Universidade Federal do Pampa-UNIPAMPA, Uruguaiana, Rio Grande do Sul, RS, Brasil

\section{Histórico do Artigo \\ Recebido em: \\ $19 / 06 / 2018$ \\ Aceito em: \\ $12 / 11 / 2018$}

\section{Palavras-chave:}

Ensino de Ciências;

Laboratórios Escolares;

Aulas Práticas;

Experimentação.

\begin{abstract}
RESUMO
Este estudo tem como objetivo analisar o ensino de ciências no Ensino Fundamental no que se refere a presença e uso dos laboratórios escolares. No RS, tais espaços são exigidos nas escolas como condição para a oferta do ensino médio no Sistema Estadual, conforme Parecer 580/2000-CEEd/RS. Por considerarmos importante que os ingressantes no ensino médio possuam essa vivência, propusemos este trabalho, que busca responder a duas indagações: existem laboratórios de ciências nas escolas públicas de Ensino Fundamental? Se existem, são utilizados? Para isso, foi feita uma pesquisa que envolveu 35 escolas públicas das cidades de Barra do Quaraí e Uruguaiana, localizadas na fronteira oeste do RS, abrangendo um público total de 1430 alunos, 46 professores da área e 37 gestores. A coleta de dados contou com aplicação de um questionário semiestruturado, contendo questões abertas e fechadas. A análise mostrou que, das 35 escolas, apenas 16 possuem laboratório de ciências, representando 45,7\%. Portanto, 19 escolas, totalizando 54,3\% estão sem laboratório. Destas, cinco oferecem o Ensino Médio, o que representa cerca de $26 \%$. Sobre o uso, dentre as que possuem, seis utilizam o espaço, com regularidade ou não, e que cinco não os utilizam. As alegações vão desde a estrutura até "falta de hábito". Com este estudo, espera-se trazer para os laboratórios um novo olhar, para que sejam utilizados como complemento às aulas de Ciências, pois a sua inserção poderá pode trazer vários benefícios, como contribuir no aumento das médias, na diminuição das faltas e na motivação do aluno em aprender ciências.
\end{abstract}

Science teaching and school laboratories in elementary school

Keywords:

Science Teaching;

School Laboratories;

Practical Classes;

Experimentation.

\begin{abstract}
This study aims to analyze the teaching of science in Elementary School regarding the presence and use of school laboratories. In the RS, such spaces are required in schools only as a condition for the provision of secondary education in the State System, according to Opinion 580/2000-CEEd / RS. However, because we consider it important that high school students have this experience, we have proposed this work, which basically seeks to answer two questions: are there science labs in public elementary schools? If they exist, are they used for practical classes and experimentation? To do this, a survey was carried out involving 35 public schools in the cities of Barra do Quaraí and Uruguaiana, located on the western border of the State of Rio Grande do Sul, covering a total audience of 1430 students, 46 teachers from the area and 37 managers. Data collection included the application of a semi-structured questionnaire, containing open and closed questions. The analysis showed that of the 35 schools involved in the research, only 16 have a science laboratory, which represents $45.7 \%$. Therefore, 19 schools, totaling a percentage of $54.3 \%$ are without laboratory. Of these, it should be noted that five (state) schools also offer high school, which represents around $26 \%$. In relation to the use, it was verified that six schools use the space, regularly or not, and that five do not use them. The allegations are lack of materials and equipment, large classes, excessive workload and even "lack of habit". With this study, it is hoped to bring to the laboratories a new look, so that they can be used as a complement to the science classes, since their insertion can bring several benefits, such as contributing to increase averages, decrease absences and motivation of the student in learning science.
\end{abstract}

*Autor correspondente: sale.santana@gmail.com (Santana S.L.C.) 


\section{Introdução}

No ensino de ciências em escolas de Ensino Fundamental da rede pública, geralmente, não se desenvolvem atividades práticas e experimentais, e os laboratórios escolares, quando existem, raramente são utilizados (1). A ausência dessas atividades pode comprometer o aprendizado das disciplinas relacionadas, uma vez que estas, ao serem ministradas, possibilitam ao aluno a vivência de experiências nas quais se pode adquirir o conhecimento de forma a sintetizá-lo, bem como o aproximam do trabalho científico (2). O uso de atividades experimentais no ensino de ciências é defendido na literatura, tendo como uma das razões a motivação, que possibilita ver na prática o que se aprende na teoria e, consequentemente, melhoria da aprendizagem (3). Outros autores (4-7), também defendem que o laboratório didático no ambiente educacional pode ser um grande aliado dos professores que realizam atividades experimentais em suas aulas. Além disso, quando a ciência é ministrada de forma que o próprio aluno tenha a oportunidade de planejar e executar seus experimentos (PBL), também pode contribuir para o enfrentamento das dificuldades cotidianas, visto que "a maioria dos problemas autênticos em nossas vidas é mal estruturada” (p. 250) (8). Nessa perspectiva, a Aprendizagem Baseada em Problemas (PBL) aliada a experiência de efetuar trabalhos em estruturas não-estruturadas poderiam preparar os alunos para, no futuro, enfrentar os desafios que permeiam o mundo real (8).

Alguns autores empenharam-se em analisar as aulas em laboratório, seja num contexto positivo, ao advertir para as finalidades das atividades práticas experimentais como contribuidoras do ensino e da aprendizagem em ciências, seja num contexto crítico, quando desaprovam a postura excessivamente empírica da ciência ou quando julgam essas atividades como sendo recuperadoras da qualidade do ensino de ciências, obrigatoriamente $(9,10)$. Desta forma, apesar de sua importância, as aulas em laboratórios não correspondem à salvação para o aprendizado de ciências, visto que outras atividades que mobilizam o envolvimento do aluno podem cumprir muito esse papel, como por exemplo, "atividades de resolução de problemas, modelamento e representação, com simulações em computador, desenhos, pinturas, colagens ou simplesmente atividades de encenação e teatro" (p. 12) (11).

Hás muitas alegações para o não uso do laboratório, que passa pela carência de pessoal técnico e más condições para a realização dos experimentos até o comportamento inadequado dos alunos num ambiente que requer cuidados extras nas atitudes (12). Aliado a isso, cita-se também a formação insuficiente do professor (13) combinada com o excessivo número de alunos por turma (14). Outro fator a ser considerado é a falta de verbas das escolas, que culmina na dificuldade cotidiana de gestores em suprir o laboratório com materiais e equipamentos mínimos, porém necessários, ao bom andamento das aulas práticas (15). É comum, ainda, encontrar laboratórios semiabandonados, mal equipados ou com equipamentos quebrados e sem estoque de reagentes (16).

No Brasil, um dado emitido pelo Censo Escolar de 2010 chama a atenção pelos números que apresenta, segundo o qual "apenas 23,8\% das escolas que ofertam Ensino Fundamental Regular, e 49,3\% das escolas do Brasil que ofertam Ensino Médio Regular apresentam laboratório de ciências" (p. 33-35) (17). Para complementar, estudos realizados apontam que apenas um pequeno número de escolas estaduais, em nível nacional, possui laboratório de ciências, sendo que muitos sem condições reais de uso $(18,19)$.

Como tentativa de melhorar os índices da educação brasileira, foi criada a Lei Federal $\mathrm{n}^{\mathrm{o}}$ 13.005/2014, que aprova o Plano Nacional de Educação (PNE), estabelecendo diretrizes, metas e estratégias de concretização no campo da educação. O PNE entrou 
em vigor no dia 26 de junho de 2014 e valerá por 10 anos. De acordo com o previsto neste Plano, a partir do momento de sua vigência, todos os planos estaduais e municipais de Educação devem ser criados ou adaptados em consonância com as diretrizes e metas estabelecidas por ele. Essas metas, num total de 20, abrangem todos os níveis de formação, desde a educação infantil até o ensino superior, com atenção para detalhes como a educação inclusiva, a melhoria da taxa de escolaridade média dos brasileiros, a formação e plano de carreira para professores, bem como a gestão e o financiamento da Educação. O PNE também dá grande peso ao financiamento e ampliação dos investimentos. Dentre essas metas, destacamos a número 7 (fomentar a qualidade da educação básica em todas as etapas e modalidades, com melhoria do fluxo escolar e da aprendizagem de modo a atingir as seguintes médias nacionais para o Ideb), que trata da educação básica e seu item 7.18 (assegurar a todas as escolas públicas de educação básica o acesso a energia elétrica, abastecimento de água tratada, esgotamento sanitário e manejo dos resíduos sólidos, garantir o acesso dos alunos a espaços para a prática esportiva, a bens culturais e artísticos e a equipamentos e laboratórios de ciências e, em cada edifício escolar, garantir a acessibilidade às pessoas com deficiência), que disserta sobre os laboratórios de ciências (p. 61-64) (20).

Acompanhando uma tendência internacional, a Base Nacional Comum Curricular (BNCC), homologado pela Portaria $n^{\circ}$ 1.570, publicada no D.O.U. de 21/12/2017, Seção 1, Pág. 146, que pretende reduzir as desigualdades educacionais no país. Essa Base busca definir o que é essencial ao ensino de todos os alunos em cada uma das etapas da vida escolar e tem como finalidade orientar os sistemas na elaboração de suas propostas curriculares, tendo como fundamento o direito à aprendizagem e ao desenvolvimento (21).

Diante disso, entendemos ser urgente dar maior visibilidade para os laboratórios escolares de ciências, dada a sua importância no ensino-aprendizagem, em consonância com o momento atual que a ciência vivencia no mundo, premiando cientistas e valorizando as iniciativas que resultem numa qualidade de vida melhor.

Considerando os aspectos ora apresentados, o presente estudo justifica-se pela possibilidade de traçar o perfil das escolas envolvidas no projeto no âmbito dos laboratórios escolares, relativo a sua presença e uso.

\section{Materiais e métodos}

Iniciou-se este trabalho após a aprovação do Comitê de Ética em Pesquisa da Universidade Federal de Santa Maria/UFSM (CAAE 0058.0.243.000-10). Na sequência, foi solicitada autorização da $10^{\mathrm{a}} \mathrm{CRE} / \mathrm{RS}$ para visitar as escolas escolhidas para participar do estudo. As visitas foram agendadas e o trabalho foi apresentado aos gestores e professores, que foram convidados a participar voluntariamente. Logo, foi passado um cronograma com as datas de realização destas visitas, onde cada responsável pela escola e pelas turmas assinou o Termo de Consentimento Livre e Esclarecido (TCLE).

Os dados a seguir derivam do estudo realizado junto às escolas pertencentes à rede pública estadual e municipal, localizadas nas áreas centrais, periféricas e rurais de cada município. Foram entrevistados 1430 estudantes, 46 professores que atuam na área de ciências e 37 gestores, abrangendo um universo de 35 escolas composto por 21 estaduais e 14 municipais, assim distribuídas: em Uruguaiana, 20 estaduais, sendo 16 em zona urbana e 04 em zona rural, incluindo uma escola rural de tempo integral; 12 municipais, sendo 08 em zona urbana e 04 em zona rural. Em Barra do Quaraí, foram visitadas 03 escolas, 01 estadual e 02 municipais, sendo 01 em zona rural. Além dos 
alunos, também participaram da pesquisa os professores vinculados à área de ciências e os gestores. Inicialmente, previa-se entrevistar apenas os diretores, entretanto, os demais componentes da direção solicitaram, de forma voluntária, responder aos questionários.

Com a finalidade de facilitar a análise, as respostas quantitativas foram tabuladas e, posteriormente, foram construídos gráficos e tabelas para representá-las. Ressalta-se que os dados utilizados neste trabalho são recortes de manifestações expressas pelos sujeitos envolvidos.

\section{Resultados e discussão}

A primeira questão apresentada aos participantes tinha como propósito saber simplesmente se na escola havia laboratório de ciências. A análise mostrou que, das 35 escolas envolvidas na pesquisa, apenas 16 possuem laboratório de ciências, o que representa $45,7 \%$. Portanto, 19 escolas, totalizando um percentual de 54,3\% estão sem laboratório. Destas, cabe destacar que cinco oferecem também o Ensino Médio. Isso significa que pouco mais da metade dos estudantes estão concluindo o ensino fundamental e ingressando no ensino médio sem ter um laboratório de ciências para a prática dos conceitos teóricos transmitidos pelos professores em sala de aula. Alguns, ainda, continuarão nessa situação no decorrer de todo o curso, possivelmente. Considerando um universo de 1430 alunos, são cerca de 782 estudantes excluídos de uma importante etapa na sua formação escolar e da sua alfabetização científica. Vale ressaltar, contudo, que embora os espaços existam, ainda assim não se pode garantir que os demais alunos tenham acesso às aulas práticas, visto que nem todos os laboratórios estão suficientemente preparados para uso.

A realidade que se pode observar nas visitas é de escolas praticamente sem laboratórios. E quando presentes, as instalações de alguns são tão inadequadas que seria impossível abrigar turmas inteiras para uma aula de qualidade, inclusive por questão de segurança. Contudo, naquelas cujo espaço é disponibilizado e a aula poderia ser ministrada com tranquilidade e bom aproveitamento, o uso efetivo não só é raro como não existe. Esse dado é preocupante, até porque cada vez mais a literatura tem reforçado a importância da experimentação no ensino de ciências, pois na medida em que se possibilita o contato com os objetos de estudo, oportuniza-se aos alunos aprimorar os conhecimentos científicos adquiridos durante as aulas teóricas. Muitos são os autores que apoiam as aulas práticas e atividades experimentais dentro dos laboratórios, defendendo que "as atividades práticas desenvolvidas como investigação podem aproximar o ensino de ciências do trabalho científico, integrando, além da parte experimental, outros aspectos próprios das ciências, em que teoria e prática constituem algo que se complementa” (p. 205), (22). Além disso, a atividade experimental, quando ministrada de forma construtivista e fundamentada na resolução de problemas, pode ajudar no desenvolvimento do raciocínio lógico e instigar o aluno a buscar soluções para equacionar os problemas. Sob esta visão, o ensino de ciências, aliado às atividades práticas, torna-se dinâmico e acaba sendo construído coletivamente.

Contudo, para que esse ideário se confirme, dois fatores são condicionantes: 1) a existência de laboratórios em condições de uso e; 2) a realização de atividades experimentais. Já verificamos a existência dos espaços, destacado no início do texto. Em relação as condições de uso e frequência, analisamos as respostas de professores e gestores, conforme consta no Quadro 1. 
Quadro 1 - Existência e uso dos laboratórios escolares, na concepção de gestores e professores.

\begin{tabular}{|c|c|c|c|c|c|}
\hline Questão & Gestores & $\mathbf{N}^{0}$ Citações & Frequência \% & Professores & $\mathbf{N}^{\circ}$ Citações \\
\hline \multirow{8}{*}{$\begin{array}{c}\text { Sobre a } \\
\text { existência dos } \\
\text { laboratórios, } \\
\text { seu uso e a } \\
\text { frequência } \\
\text { com que } \\
\text { ocorre }\end{array}$} & Não respondeu & 3 & 8,1 & Não respondeu & 1 \\
\hline & Não tem laboratório & 19 & 51,4 & $\begin{array}{c}\text { Não tem } \\
\text { laboratório }\end{array}$ & 19 \\
\hline & Poucas vezes & 3 & 8,1 & Poucas vezes & 5 \\
\hline & Está em reforma & 2 & 5,4 & $\begin{array}{l}\text { Usa-se outros } \\
\text { espaços }\end{array}$ & 2 \\
\hline & Não é utilizado & 2 & 5,4 & Não é utilizado & 9 \\
\hline & $\begin{array}{c}\text { O laboratório de } \\
\text { química é utilizado }\end{array}$ & 1 & 2,7 & $\begin{array}{l}\text { Usa-se de acordo } \\
\text { com o conteúdo }\end{array}$ & 5 \\
\hline & Com frequência & 7 & 18,9 & Com frequência & 5 \\
\hline & Total & 37 & 100 & Total & 46 \\
\hline
\end{tabular}

Durante a visita e aplicação do questionário, indagamos o motivo da não realização de atividades naquelas escolas cujos espaços existem. Obtivemos como resposta as colocações ordenadas no Quadro 2, que foram devidamente selecionadas em função das múltiplas razões expostas pelos entrevistados. Igualmente, apuramos que as atividades e aulas práticas ocorrem onde não há laboratórios, utilizando recintos pouco adequados, como cozinha, pátio e a própria sala de aula. Os materiais, conforme relato, são confeccionados pelos professores e alunos. Desta forma, com base nos relatos de gestores e professores constantes no Quadro 2, podemos inferir que o aspecto mais citado para a não realização dessas atividades refere-se ao de natureza pedagógica, em especial a inexistência do laboratório. Em relação a falta de tempo, ressaltamos que, de modo geral, a etapa concebida para preparação das aulas não integra a carga horária docente. Também se obteve uma resposta que cabe destacar: segundo alguns professores, o laboratório "é devidamente equipado, falta é o hábito de ocupá-lo”.

Quadro 2 - Considerações de gestores e professores para a não utilização do laboratório.

\begin{tabular}{|c|l|}
\hline \multirow{5}{*}{ Gestores } & $\begin{array}{l}\text { "Laboratório está em reforma" } \\
\text { "Faltam materiais/equipamentos" } \\
\text { "Não tem pessoal capacitado para auxiliar" } \\
\text { "professores estão pouco preparados para trabalhar e muitos nem querem" }\end{array}$ \\
\hline Professores & $\begin{array}{l}\text { "O número de alunos é muito grande para o tamanho do laboratório" } \\
\text { "falta materiais e equipamentos } " \\
\text { "foi necessário transformar o laboratório em sala de aula" } \\
\text { Carga horária completa" }\end{array}$ \\
\hline
\end{tabular}

Sobre infraestrutura de laboratórios escolares, a literatura apresenta uma gama de autores que já se debruçaram sobre o tema e trouxeram relevantes informações, iniciando pela localização, sugerida que seja no andar térreo, com portas de saídas para pátios abertos que permita a evacuação rápida dos alunos em caso de emergência. Acerca do espaço físico, destaca-se que o tamanho ideal seja de aproximadamente $90 \mathrm{~m}^{2}$, com capacidade para abrigar, no máximo, 30 alunos (2), representando $3 \mathrm{~m}^{2}$ por aluno. Para abrigar material portátil e garantir espaço para circulação, acrescenta-se a isso mais $1,5 \mathrm{~m}^{2}$, totalizando $4,50 \mathrm{~m}^{2}$ por aluno (23). Em relação à iluminação, sugere-se 
que a cada 1,5m tenha-se uma lâmpada instalada, embora isso seja determinado pela extensão do local (24). Estas devem ser de material que não alterem a temperatura do ambiente. Outros elementos destacados são a localização de pias e tanques, piso e parede ideal, ventilação e outros tópicos essenciais ao bom funcionamento do local e aproveitamento das práticas laboratoriais (24).

Porém, em visita às escolas o que se encontra é uma grande diversidade de condições físicas e estruturais dos espaços. Assim, enquanto para umas a escolha foi mantê-los ativos apesar das adversidades, para outras a melhor opção foi desativá-los e reciclar os espaços, muitas vezes por falta de opção devido ao crescimento de turmas na proporção inversa ao do espaço físico.

A Figura 1 mostra a quantidade de alunos em cada turma, bem como quantas turmas cada escola possui. É possível verificar o número elevado de alunos em algumas turmas, na contramão dos padrões citados acima. A Figura 2 mostra fotos que destacam a realidade das escolas sobre as condições dos laboratórios, que muitas vezes servem também como local para arquivar documentos. Cabe ressaltar que, em alguns casos, o laboratório consistia em uma sala com armário e alguns animais (répteis, especialmente) dentro de potes de vidro.

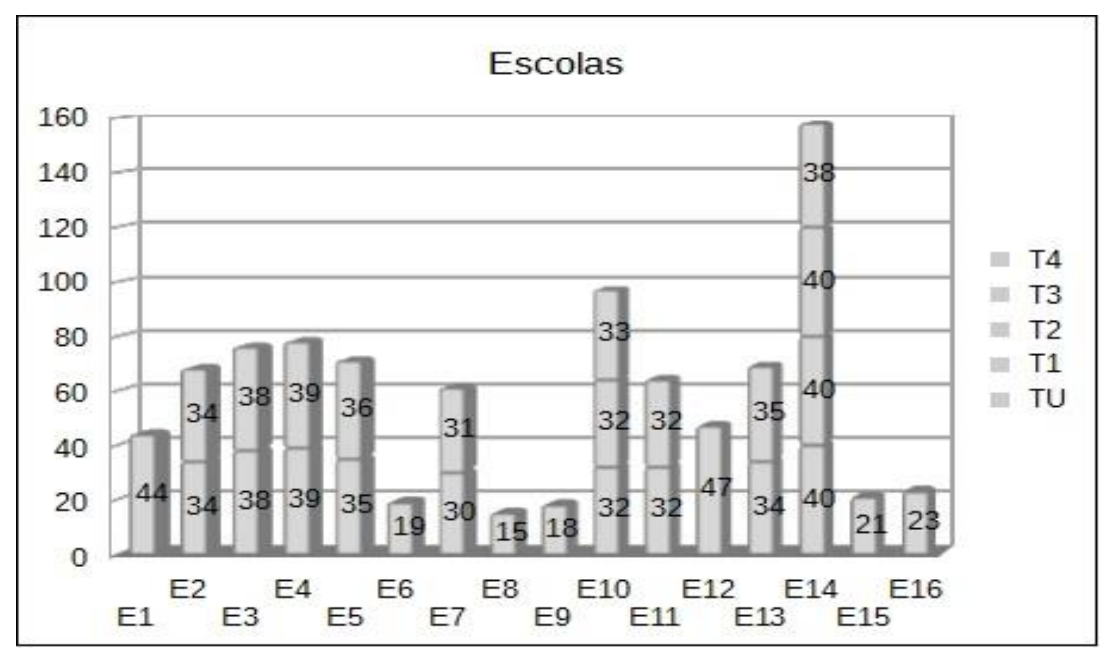

Figura 1 - Número de alunos por turma, onde TU (Turma Única), T1, T2, T3 e T4 (número de turmas por escolas).
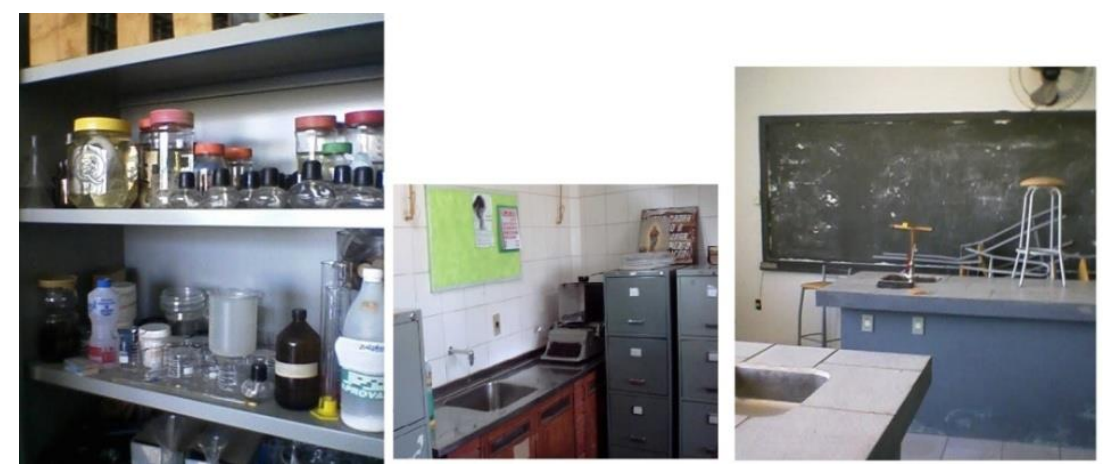

Figura 2 - Situação dos laboratórios de algumas escolas participantes da pesquisa. Fonte: Cláudia Alves Ortiz Barreto.

Apesar desse cenário de instalações inadequadas e turmas excessivamente constituídas, as atividades experimentais não deixam de ocorrer, como foi possível verificar na análise das respostas de professores e gestores, destacado no Quadro 1 . Na 
literatura, há defensores de aulas práticas em qualquer sala de aula, visto que a alegação de falta de laboratórios, materiais e equipamentos não pode ser fator condicionante para a privação de atividades experimentais no ensino de ciências, química, física e biologia (25). Ademais, a realização dessas atividades podem promover "a interatividade entre $o$ aprendiz e o objeto de estudo" (p. 85) (26). Importante ressaltar, contudo, diferentes opiniões acerca do uso do laboratório didático e a inserção de atividades experimentais. É inegável a sua importância. Entretanto para que não se torne mais uma ação fracassada no sistema, é preciso que esta inserção seja implementada de maneira racional, promovendo um ensino que busque a aproximação dos estudantes com seu cotidiano, "atuando como mecanismo favorecedor da aprendizagem em suas diferentes dimensões pedagógicas" (p. 265) (27). Se o que foi exposto na sala de aula e o que foi obtido no laboratório não se constituir em algo que se complementa, não houve integração entre teoria e prática (1). Sendo assim, as atividades experimentais "não passam de ativismo" (p. 197) (1).

O Quadro 3 traz a visão dos alunos acerca das indagações sobre os laboratórios e as aulas práticas de ciências em suas escolas.

Quadro 3 - Uso do laboratório, apreciação de sua existência e utilidade das aulas práticas, na visão dos alunos.

\begin{tabular}{|c|c|c|c|c|c|}
\hline Questão & Descrição & Estaduais & Municipais & Total & Frequência \% \\
\hline \multirow{3}{*}{$\begin{array}{c}\text { Você tem aulas práticas em } \\
\text { laboratório de ciências? }\end{array}$} & Sim & 114 & 370 & 484 & 33,9 \\
\cline { 2 - 6 } & Não & 693 & 195 & 888 & 62,1 \\
\cline { 2 - 6 } & Não respondeu & 55 & 3 & 58 & 4 \\
\cline { 2 - 6 } & Total & $\mathbf{8 6 2}$ & $\mathbf{5 6 8}$ & $\mathbf{1 4 3 0}$ & $\mathbf{1 0 0}$ \\
\hline \multirow{2}{*}{$\begin{array}{c}\text { Caso negativo, gostaria de } \\
\text { ter laboratório e aulas } \\
\text { práticas? }\end{array}$} & Sim & 715 & 219 & 934 & 65,3 \\
\cline { 2 - 6 } & Não & 20 & 6 & 26 & 1,8 \\
\cline { 2 - 6 } & Não respondeu & 127 & 343 & 470 & 32,9 \\
\cline { 2 - 6 } & Total & $\mathbf{8 6 2}$ & $\mathbf{5 6 8}$ & $\mathbf{1 4 3 0}$ & $\mathbf{1 0 0}$ \\
\hline \multirow{3}{*}{$\begin{array}{c}\text { Aulas práticas o ajudariam a } \\
\text { entender o conteúdo teórico? }\end{array}$} & Sim & 732 & 517 & 1249 & 87,3 \\
\cline { 2 - 6 } & Não & 38 & 27 & 65 & 4,6 \\
\cline { 2 - 6 } & Tospondeu & 92 & 24 & 116 & 8,1 \\
\hline \multirow{2}{*}{\begin{tabular}{c} 
Total \\
\hline
\end{tabular}} & $\mathbf{8 6 2}$ & $\mathbf{5 6 8}$ & $\mathbf{1 4 3 0}$ & $\mathbf{1 0 0}$ \\
\hline
\end{tabular}

Dando segmento aos objetivos da pesquisa, passamos a analisar a percepção dos alunos sobre o ensino de ciências e a relação com seu cotidiano (Quadro 4), bem como a qualidade das aulas práticas aplicadas por seus professores (Quadro 5). Sobre o termo cotidiano, comumente, este tem sido utilizado para relacionar situações habituais ligadas ao dia a dia dos indivíduos com conhecimentos científicos, ou seja, é um ensino de conteúdos relacionados a fenômenos que ocorrem na vida diária das pessoas com vistas à aprendizagem de conceitos $(28,29,30)$. Afinal, "a sala de aula não é um espaço fechado e acabado em si, pois o mundo externo faz parte, seja através dos sujeitos, seja através dos referenciais teóricos e curriculares" (p. 270) (31). Entretanto, “ainda se "transmite o conhecimento, desestimulando o questionamento" (p. 3-4) (32). Comumente, o discurso educacional não condiz com a prática educativa, pois esta desestimula o "aprender a aprender" (p. 4) (32). E é isso que possibilita ao educando lidar positivamente com a mudança, permitindo sua sobrevivência. A experimentação, seja ela do tipo que for (show, ilustrativa, investigativa ou problematizadora), "é capaz de motivar alunos a construírem perguntas relacionadas ao que acontece na natureza durante seu dia a dia” (p. 151) (33), buscando respostas as suas questões. A aprendizagem é um processo continuado, e no currículo deveria constar também os 
temas relevantes para a comunidade escolar, "[...] tratados ano a ano, com níveis crescentes de informação e integração a outros conteúdos" (p. 49) (34). No que se refere ao ensino de química, especificamente, o termo "cotidiano" é amplamente conhecido e, segundo a maioria, trata-se de uma abordagem fácil de ser posta em prática. Esse tipo de consenso predomina, principalmente, entre professores do ensino médio (35). Sobre a atividade experimental, não é raro que estas acabem se reduzindo amera observação por parte dos alunos (36), constituindo-se como um ponto negativo. Conduzir uma aula prática caracterizada nesse modelo, pressupõe-se banalizar este importante recurso para o ensino de Ciências, pois "assim como em qualquer aprendizagem, o ato de aprender ciências exige motivação" (p. 116) (37). O ensino experimental não pode ser simplesmente relegado ao papel de recurso auxiliar.

Neste sentido, o que se procurou saber dos alunos através da questão formulada na pesquisa é se eles consideram que o conteúdo de ciências ministrado na sala de aula os ajuda, de alguma forma, a compreender melhor os fenômenos que ocorrem em seu dia a dia, e se é possível relacioná-lo e utilizá-lo em sua vida cotidiana. Também lhes foi solicitado uma avaliação das aulas práticas. Devido ao leque diversificado das respostas e pensando em clarificar a questão, foi elaborado o Quadro 4, fundamentado no relato dos alunos.

Quadro 4 - Avaliação dos alunos em relação às aulas práticas de ciências realizadas em laboratório e sua relação com o cotidiano.

\begin{tabular}{|c|c|c|c|c|c|}
\hline Questão & Descrição & Estaduais & Municipais & Total & Frequência\% \\
\hline \multirow{3}{*}{$\begin{array}{c}\text { Qual a sua } \\
\text { definição sobre }\end{array}$} & Regular & 204 & 175 & 379 & 26,5 \\
\cline { 2 - 6 } as aulas práticas? & Boa & 123 & 123 & 246 & 17,2 \\
\cline { 2 - 6 } & Ótima & 75 & 61 & 136 & 9,5 \\
\cline { 2 - 6 } & Nenhuma & 460 & 209 & 669 & 46,8 \\
\hline \multirow{2}{*}{$\begin{array}{c}\text { As aulas de } \\
\text { ciências possuem } \\
\text { relação com seu } \\
\text { dia a dia? }\end{array}$} & Total & $\mathbf{8 6 2}$ & $\mathbf{5 6 8}$ & $\mathbf{1 4 3 0}$ & $\mathbf{1 0 0}$ \\
\cline { 2 - 6 } & Não & 77 & 81 & 158 & 11 \\
\cline { 2 - 6 } & Sim & 609 & 422 & 1031 & 72,1 \\
\hline \multirow{2}{*}{ dim } & Total & 176 & 65 & 241 & 16,9 \\
\hline
\end{tabular}

Percebe-se, nessas questões, que foi elevado o número de estudantes que preferiram não classificar as aulas, optando pela abstenção. Entende-se que para eles não há uma definição conclusa sobre a qualidade das aulas práticas nem tampouco sobre sua relação com seu cotidiano. Credita-se isso mais ao fato de não haver laboratórios do que ausência de opinião ou avaliação negativa. A média de idade dos alunos é de 14 anos, porém nas escolas estaduais $66 \%$ tem entre 14 a 16 anos e nas escolas municipais o percentual é de $63 \%$ para uma faixa etária entre 13 a 14 anos. Lembramos que a pesquisa abrangeu somente os alunos finalistas do ensino fundamental. Já na parte qualitativa (resposta ao Por quê?) a participação foi um pouco mais expressiva, como podemos comprovar no Quadro 5, onde destacamos as respostas obtidas em maior número, unificadas para melhor entendimento. Essa diferença pode ser analisada sob o seguinte ângulo: se as aulas foram classificadas como Regular por 485 alunos, pode ser em virtude da baixa frequência ao local e da falta de suporte, que dificulta uma avaliação mais precisa; se para 440 elas foram consideradas Boa, a razão pode estar no maior aprendizado e na participação, já que os alunos destacaram isso na pesquisa; a classificação Ótima, apontada por 101 participantes demonstra que as aulas práticas ocorrem e agregam conhecimento. Isto acontece nas escolas que detém laboratórios e recorrem ao espaço regularmente. Já sobre a relação Ciências x Cotidiano percebe-se 
um equilíbrio maior entre as respostas negativas. A discrepância entre as respostas positivas pode ser inferida pela dificuldade de se expressar e opinar dos alunos, verificada durante a aplicação do questionário. Ausência de aulas e/ou laboratórios justificam outras divergências.

Quadro 5 - Avaliação dos alunos em relação às aulas práticas de ciências realizadas em laboratório e importância destas.

\begin{tabular}{|c|c|c|c|c|c|}
\hline $\begin{array}{c}\text { Questão } \\
\text { Dissertativa }\end{array}$ & Alunos Estaduais & $\begin{array}{c}\mathrm{N}^{\mathbf{o}} \\
\text { Citações }\end{array}$ & Alunos Municipais & $\begin{array}{c}\mathrm{N}^{\mathbf{o}} \\
\text { Citações }\end{array}$ & Total \\
\hline \multirow{6}{*}{$\begin{array}{c}\text { Qual a sua } \\
\text { definição sobre } \\
\text { as aulas } \\
\text { práticas? }\end{array}$} & $\begin{array}{c}\text { Não vamos com frequência; } \\
\text { não tem suporte }\end{array}$ & 194 & $\begin{array}{c}\text { Não vamos com frequência; } \\
\text { não tem suporte }\end{array}$ & 291 & 485 \\
\hline & $\begin{array}{l}\text { Aprendemos muito mais que } \\
\text { em sala/Participamos mais }\end{array}$ & 298 & $\begin{array}{l}\text { Aprendemos muito mais que } \\
\text { em sala/Participamos mais }\end{array}$ & 142 & 440 \\
\hline & $\begin{array}{l}\text { Para nosso aprendizado } \\
\text { é fundamental }\end{array}$ & 14 & $\begin{array}{l}\text { Para nosso aprendizado } \\
\text { é fundamental }\end{array}$ & 87 & 101 \\
\hline & Outras razões & 77 & Outras razões & 23 & 100 \\
\hline & Não respondeu & 279 & Não respondeu & 25 & 304 \\
\hline & Total & 862 & & 568 & 1430 \\
\hline \multirow{6}{*}{$\begin{array}{c}\text { As aulas de } \\
\text { ciências } \\
\text { possuem } \\
\text { relação com seu } \\
\text { dia a dia? }\end{array}$} & $\begin{array}{c}\text { Não serve para nada, pois } \\
\text { não relaciona com } \\
\text { o cotidiano }\end{array}$ & 124 & $\begin{array}{c}\text { Não serve para nada, pois } \\
\text { não relaciona com } \\
\text { o cotidiano }\end{array}$ & 22 & 146 \\
\hline & $\begin{array}{l}\text { Algumas vezes sim, } \\
\text { outras não }\end{array}$ & 97 & $\begin{array}{l}\text { Algumas vezes sim, } \\
\text { outras não }\end{array}$ & 102 & 199 \\
\hline & $\begin{array}{c}\text { Porque nos ajuda a } \\
\text { compreender melhor os } \\
\text { acontecimentos (higiene, } \\
\text { doenças, meio ambiente, } \\
\text { vida, animais) }\end{array}$ & 298 & $\begin{array}{c}\text { Porque nos ajuda a } \\
\text { compreender melhor os } \\
\text { acontecimentos (higiene, } \\
\text { doenças, meio ambiente, } \\
\text { vida, animais) }\end{array}$ & 158 & 456 \\
\hline & Outras razões & 89 & Outras razões & 56 & 145 \\
\hline & Não respondeu & 254 & Não respondeu & 230 & 484 \\
\hline & Total & 862 & & 568 & 1430 \\
\hline
\end{tabular}

Atividades experimentais são "um recurso de inegável valor no ensino $e$ aprendizagem das ciências” (p. 193) (38). Neste sentido, as aulas de laboratório podem atuar como contraponto das aulas teóricas, fomentando o processo de aquisição de novos conhecimentos. A vivência de certa experiência realizada em laboratório ou na própria sala de aula pode facilitar a fixação do conteúdo a ela relacionado, estimulando a criatividade dos alunos e desenvolvendo seu perfil investigativo (39). Desta forma, mesmo que se se tenha conhecimento dos fatores limitantes para a realização de aulas práticas em laboratório, a oferta de um pequeno número de atividades experimentais, desde que interessantes e desafiadoras, já será suficiente para propiciar um contato direto com os fenômenos estudados teoricamente, identificar questões de investigação, organizar e interpretar os dados resultantes. Para ensinar ciências de maneira efetiva é necessário primar por essas características e tentar desenvolvê-las junto as novas gerações de estudantes (37). Destacam-se, então, cinco atitudes ou valores que o experimento construtivista possibilita: valoriza a compreensão; incentiva as atitudes questionadoras; promove a autonomia; valoriza a cooperação e o trabalho em grupo; e promove a atitude de pesquisa (40).

Como forma de complementar este trabalho, pedimos a professores e gestores que 
respondessem a um último questionamento: "Caso sua escola não possua laboratório, você ajudaria na implantação de um?”. A resposta positiva foi unânime, embora ressaltando as dificuldades peculiares de cada um, como carga horária excessiva, escassez de recursos financeiros, ausência de espaço físico, entre outros. Tanto professores quanto gestores lamentam a falta deste importante espaço didático em suas escolas, visto ser uma ferramenta que poderia trazer muitos benefícios ao educando. Não poderia ser diferente, já que, apesar dos entraves legitimamente reconhecidos, enquanto profissionais da educação cabe a eles refletir sobre o compromisso de agir para uma mudança estrutural e funcional de sua escola (41). Corroborando, temos uma afirmação sobre o compromisso do educador: "a primeira condição para que um ser possa assumir um ato comprometido está em ser capaz de agir e pensar”. (p.16) (42).

\section{Considerações Finais}

A pesquisa realizada nas escolas, com a aplicação de questionários e visita in loco aos laboratórios, buscava especificamente saber se as escolas possuíam ou não laboratórios de ciências, e, em caso positivo, se estes eram utilizados para aulas práticas e atividades experimentais.

Os resultados apontaram que os laboratórios não existem na maioria das escolas e que quando existem não estão adequados para uso ou então não são utilizados meramente por desinteresse. Contudo, mostraram também que essa inexistência não impede a realização de aulas práticas, bem como de experimentos, visto que muitos professores usam de sua criatividade para driblar a carência de recursos e de espaço físico. Este processo investigatório permitiu, ainda, alertar para a possibilidade de que o ensino de ciências poderá ser mais prazeroso e a aprendizagem mais significativa com a inserção de atividades experimentais, podendo representar uma alternativa metodológica para os estudantes, principalmente nas séries finais do Ensino Fundamental. Notadamente, algumas pesquisas abordando o tema aulas práticas e atividades experimentais no ensino de ciências têm apontado o professor, em primeira escala, como o maior responsável por esta ausência. Entretanto, pelo relato de gestores e professores foi possível constatar que o problema faz parte de uma escala maior, já que os recursos recebidos pelas escolas para manutenção não cobrem todos os custos. Desta forma, é necessário fazer escolhas cruciais que acabam por afetar esses espaços em prol de dificuldades consideradas mais relevantes e urgentes pela comunidade escolar. Porém, mesmo diante desses obstáculos faz-se necessário uma reflexão sobre a importância de se manter os laboratórios ativos e que estes sejam de fato utilizados, uma vez que, ao se aplicar somente aulas teóricas ou empregar apenas um método de ensino, o aluno poderá se tornar desinteressado e pouco participativo, além de não conseguir estabelecer uma ligação entre conceitos teóricos e o seu cotidiano. Além disso, o diagnóstico obtido com a coleta de dados proporcionou uma visão ampla de outras questões que não são o foco principal do trabalho, mas que contribuem com a visibilidade que se pretende dar aos espaços. Este esboço do atual panorama, que fica como legado às escolas, almeja sensibilizar gestores e professores para que meditem acerca desse tema e de sua relevância, podendo ampará-los em futuras decisões. Observadas essas considerações, ressaltamos que o propósito elementar deste trabalho foi verificar aspectos relacionados à presença e uso dos laboratórios de ciências em escolas da rede pública dos municípios de Barra do Quaraí e Uruguaiana.

Apenas para complementar tudo que já foi exposto, trazemos uma reflexão ao concluir este trabalho: "Sem experimentos não há aprendizado [...]. Expor previsões a situações reais é o que faz a ciência moderna. Apresentar esse conhecimento como fórmulas a 
decorar é fazer uma caricatura distorcida do que é a ciência” (p. 77) (42).

\section{Referências}

1. Rosito BA. O ensino de Ciências e a experimentação. In: Moraes R. Construtivismo e Ensino de Ciências: Reflexões Epistemológicas e Metodológicas. $2^{a}$ ed. Porto Alegre. Editora EDIPUCRS, 2003. 195-208.

2. Krasilchik M. Prática de ensino em biologia. 4. ed. São Paulo: Editora da Universidade de São Paulo-USP; 2004.

3. Salvadego WNC. A atividade experimental no ensino de química: uma relação com o saber profissional do professor da escola média [dissertação]. Londrina: Universidade Estadual de Londrina; 2007.

4. Cruz JB. Laboratórios. Brasília: Universidade de Brasília; 2009.

5. Pinho JAF. Atividades experimentais: do método à prática construtivista [tese]. Florianópolis: Universidade Federal de Santa Catarina; 2000.

6. Capelleto JA. Biologia e educação ambiental: Roteiros de trabalho. São Paulo: Ática; 1992.

7. Krasilchik M. Prática de ensino de biologia. 2aed. São Paulo: Haper e Row do Brasil Ltda; 1986.

8. Folmer V, da Rocha JBT, Barbosa NBV, Soares FAA. Experimental activities based on ill-structured problems improve Brazilian school student's understanding of the nature of scientific knowledge. Revista Electrónica de Enseñanza de las Ciencias 2009; 8 (1): 232-254.

9. Gusmão G, Goldbach T, Capilé BR. Reflexões sobre materiais de apoio para atividades práticas para o ensino de biologia: percepções de docentes e de licenciandos. Revista Ciências \& Ideias 2011; 3 (1): 1-13.

10. Araujo MST, Abib MLVS. Atividades experimentais no ensino de física: diferentes enfoques, diferentes finalidades. Revista Brasileira de Ensino de Física 2003; 25(2): 176-194.

11. Borges AT. Novos rumos para o laboratório escolar de ciências. Caderno Brasileiro de Ensino de Física 2002; 19(3): 291-313.

12. Machado PFL, Mól GS. Experimentando química com segurança. Revista Química Nova Na Escola 2008; 27: 57-60.

13. Nardi R. Questões atuais no ensino de ciências. São Paulo: Escrituras; 1998.

14. Silva RR, Machado PFL. Experimentação no ensino médio de química: a necessária busca da consciência ético-ambiental no uso e descarte de produtos químicos - um estudo de caso. Ciência \& Educação 2008; 14 (2): 233-249.

15. Oliveira PS, Nascimento MC, Bianconi ML. Mudanças conceituais ou comportamentais? Ciência e Cultura 2005; 57 (4): 46-47.

16. Gioppo C, Scheffer EWO, Neves MCD. O ensino experimental na escola fundamental: uma reflexão de caso no Paraná. Educar 1998; 14: 39-57.

17. Ministério da Educação. Instituto Nacional de Estudos e Pesquisas Educacionais Anísio Teixeira. Resumo Técnico - Censo Escolar. Brasília (DF); 2010.

18. Moreira ML, Diniz RES. O laboratório de biologia no ensino médio: infraestrutura e outros aspectos relevantes. Núcleos de Ensino 2003; 1: 295-305.

19. Maia DP. Utilização de laboratórios em algumas escolas de ensino médio de Manaus. Revista AretéRevista Amazônica de Ensino de Ciências 2010; 3 (5): 5-15.

20. Ministério da Educação. Plano Nacional de Educação 2014-2024. Brasília (DF); 2014.

21. Brasil. Base Nacional Comum Curricular. [internet] Ministério da Educação e Cultura. [atualizado em 2017; citado em 03 de Fev. 2018]. Disponível em: http://basenacionalcomum.mec.gov.br/images/pdf/1_BNCC-Final_Introducao.pdf.

22. Moraes R. Construtivismo e ensino de ciências: reflexões epistemológicas e Metodológicas. Porto Alegre: EDIPUCRS; 2000.

23. Weissmann H. Didática das ciências naturais: contribuições e reflexões. Porto Alegre: Artmed; 1998.

24. Lima AC, Rocha ZFD. Como montar um laboratório de ciências. [Internet]. 2012 [acesso em 10 Out. 2017]. Revista Nova Escola. 17. Disponível em: http://revistaescola.abril.com.br/gestaoescolar/ 
como-montar-laboratorio-ciencias-completo-648551.shtml.

25. Borges AT. O papel do laboratório no ensino de ciências. In Moreira MA, Zylberszta JNA, Delizoicov D \& Angotti JAP. Atas do I Encontro Nacional de Pesquisa em Ensino de Ciências; 1997 Nov 27-29; Porto Alegre: Editora da Universidade-UFRGS; 1997. 2-11.

26. Pinto VF, Viana AP, Oliveira AEA. Impacto do laboratório didático na melhoria do ensino de ciências e Biologia em uma escola pública de Campos dos Goytacazes/Rj. Revista Conexão 2013; 9(1) 84-93.

27. Rosa CW, Rosa AB, Pecatti C. Atividades experimentais nas séries iniciais: relato de uma investigação. Revista Electrónica de Enseñanza de las Ciencias 2007; 6 (2): 263-274.

28. Duré RC, Andrade MJD, Abílio FJP. Ensino de biologia e contextualização do conteúdo: quais temas o aluno de ensino médio relaciona com o seu cotidiano? Revista Experiências em Ensino de Ciências 2018; 13 (1): 259-272.

29. Delizoicov D, Angotti JA, Pernambuco MM. Ensino de Ciências: fundamentos e métodos. $4^{\mathrm{a}}$ ed. São Paulo: Cortez; 2002.

30. Santos WLP, Mortimer EF. Concepções de professores sobre contextualização social do ensino de química e ciências. In: 22a Reunião Anual da Sociedade Brasileira de Química, Poços de Caldas (MG) 25-28 mai, 1999. Livro de Resumos, 3, Ed 070. São Paulo: Cortez; 2002.

31. Uhmann RIM, Conte II. Aprender e ensinar química para quê? Revista Educação 2011; 36 (2): 265-278.

32. Moreira MA. Aprendizagem significativa crítica. [Internet]. 2000 [acesso em 20 nov 2017]. In Anais do $3^{\circ}$ Encontro Internacional sobre Aprendizagem Significativa; 2000 set 11-15; Lisboa, Portugal.Publicada nas Atas desse Encontro, 33-45, com o título original de Aprendizagem significativa subversiva. Publicada também em Indivisa, Boletín de Estúdios e Investigación, $\mathrm{n}^{\circ}$ 6, pp. 83-101, 2005, com o título Aprendizaje Significativo Crítico. $1^{\mathrm{a}}$ edição, em formato de livro, 2005; $2^{\mathrm{a}}$ edição 2010; ISBN 85-904420-7-1. Disponível em http://www.if.ufrgs.br/ moreira/apsigcritport.pdf.

33. Taha MS, Lopes CSC, Soares EL, Folmer V. Experimentação como ferramenta pedagógica para o ensino de ciências. Experiências em Ensino de Ciências 2016;11 (1): 138-154.

34. Lanes KG, Lanes DVC, Pessano EFC, Folmer V. O Ensino de Ciências e os Temas Transversais: sugestões de eixos temáticos para práticas pedagógicas no contexto escolar. Revista Contexto \& Educação 2014; 29 (92): 21-51.

35. Wartha EJ, Silva EL. Bejarano NRR. Cotidiano e contextualização no ensino de química [Internet]. 2013 [acesso em 20 nov 2017]. Revista Química Nova na Escola. São Paulo (SP), 35(2): 84-91. Disponível em: http://qnesc.sbq.org.br/online/qnesc35_2/04-CCD-151-12.pdf.

36. Rosa DC, Rossetto GAR da S, Terrazzan EA. Educação em ciências na pré-escola: implicações para a formação de professores. Revista Educação 2003; 28(1): 85-92

37. Trivelato SF, Silva RLF. Atividade lúdica e ensino de ciências-a biodiversidade como exemplo. Coleção Ideias em Ação. Ensino de ciências. São Paulo: Cengage Learning; 2011.

38. Dourado L. Concepções e práticas dos professores de Ciências Naturais relativas à implementação integrada do trabalho laboratorial e do trabalho de campo. Revista Electrónica de Enseñanza de lãs Ciencias 2012; 5(1): 192-212.

39. Capeletto A. Biologia e Educação Ambiental: Roteiros de trabalho. São Paulo: Ática; 1999.

40. Borges RMR, Moraes R. Educação em Ciências nas Séries Iniciais. Porto Alegre: Sagra Luzatto; 1998.

41. Moro CR, Grabauska C. Educação ambiental e cidadania - uma prática escolar. Revista Educação 2001;26 (1) jan/jun.

42. Freire P. A importância do ato de ler. 29a ed. São Paulo: Cortez; 1994.

43. Bizzo N. A escola que os jovens merecem. [entrevista a Ana Aranha] Revista Época Especial Educação 2009 ago ed. 587. p. 77. Disponível em <http://revistaepoca.globo.com/revista/ epoca/0, emi87998-15223-5,00-a+escola+que+os+jovens+merecem.html>. Acesso em 14 fev. 2018. 